\title{
Suboptimal medication-related quality of care preceding hospitalisation of older patients
}

\begin{abstract}
hronic diseases are the leading cause of death and disability worldwide, and their prevalence is increasing, particularly in the older population. ${ }^{1}$ In Australia, chronic diseases account for $70 \%$ of total health expenditure, costing $\$ 91.2$ billion in the 2010-11 financial year. ${ }^{2}$ Optimal management of chronic disease therefore has significant potential to reduce health care expenditure, as well as improve health outcomes for individuals.
\end{abstract}

In Australia, it is estimated that between $2 \%$ and $3 \%$ of all hospital admissions are medication related. ${ }^{3}$ There were 9.3 million hospital separations in Australia during 2011-2012 at an average cost of $\$ 5204$ per separation; this suggests that there are about 232500 medication-related admissions per year at an annual cost of $\$ 1.2$ billion. ${ }^{4}$ Many of these hospitalisations could potentially be prevented by delivery of appropriate primary care. ${ }^{3}$

To facilitate the reduction of medication-related morbidity, clinical indicators have been developed that assess processes of care associated with medication use and ensuing adverse outcomes of hospitalisation. ${ }^{5,6}$ These medicationrelated clinical indicator sets were originally developed more than 10 years ago by expert panels in the United States, United Kingdom and Canada, based on the principles that medication-related problems are recognisable, that the adverse outcomes are foreseeable, and that their causes and outcomes are identifiable and controllable. On the basis of these clinical indicators, it has been reported that between $3 \%$ and $20 \%$ of hospitalised patients had suboptimal care before admission, depending on the country and population studied. $^{7-9}$

Clinical indicators have been widely adopted as a measure of health system performance and quality of care

\section{Abstract}

Objective: To examine the prevalence of suboptimal medication-related processes of care before the hospitalisation of older patients.

Design and setting: We conducted a retrospective cohort study using a clinical indicator set related to medication management that has been validated by an expert panel as consisting of suboptimal aspects of medication use that clinicians should be able to foresee and avoid. Australian Government Department of Veterans' Affairs administrative claims data between 1 July 2007 and 30 June 2012 were analysed according to these clinical indicators to assess medication-related processes of care preceding hospitalisation.

Participants: Veterans with one or more hospitalisations in Australia for a condition defined by the clinical indicator set.

Main outcome measure: Prevalence of suboptimal medication-related processes of care before hospitalisation as a proportion of all hospitalisations defined by diagnoses in the clinical indicator set.

Results: During the 5-year study period, there were 164813 hospitalisations with primary diagnoses for conditions included in the clinical indicator set, encompassing 83430 patients. The overall proportion of hospitalisations that were preceded by suboptimal medication-related processes of care was $25.2 \%$ (41 546 hospitalisations); $34.5 \%$ of patients (28 807 patients) had at least one hospitalisation and $10.4 \%$ (8640 patients) had two or more hospitalisations preceded by suboptimal medication-related processes of care. At least one in 10 hospitalisations for chronic heart failure, ischaemic stroke, asthma, gastrointestinal ulcer or bleeding, fracture, renal failure or nephropathy, hyperglycaemia or hypoglycaemia were preceded by suboptimal medication-related processes of care.

Conclusions: This study highlights conditions for which there are evidence-practice gaps in medication management in the older population. Routine prospective monitoring of these evidence-based, validated, medication-related clinical indicators provides a means for quality improvement in the management of common chronic conditions.

provided to patients, ranging from the acute care to primary care settings, across a number of disease states. ${ }^{10}$ Use of clinical indicators to determine the appropriateness and timeliness of care for patients with chronic disease and associated medication use is a potentially underused measure for assessing health system performance. Such indicators may facilitate the identification of areas with potential for improving health care and health outcomes, as well as reducing the frequency of adverse events.

We have developed evidence-based medication-related indicators of suboptimal processes of care before hospitalisation that are specific to the Australian health care setting. ${ }^{11}$ The indicators are based on Level III or greater evidence, and were validated by an expert panel as aspects of medication use that clinicians should be able to identify and resolve in primary care. ${ }^{12}$ The aim of this study was to apply these medicationrelated clinical indicators to investigate the prevalence of suboptimal medication-related processes of care preceding hospitalisation of older patients.

\section{Methods}

Ethics approval for this study was obtained from the Human Research Ethics Committees of the University of South Australia (protocol number 0000025588) and the Department of 
Veterans' Affairs (DVA) (protocol number E012/003).

\section{Data source}

We analysed DVA administrative health claims data to determine the prevalence of clinical indicators of suboptimal medication-related processes of care before hospitalisation in a treatment population of about 300000 veterans during the study period (1 July 2007 to 30 June 2012). The DVA claims database contains patient-specific demographic data, including date of birth, date of death, sex, level of entitlement and residential status, as well as details of all prescription medicines, medical and allied health services, and hospitalisations provided to veterans for which the DVA pays a subsidy. Medicines are coded in the dataset according to the World Health Organization anatomical and therapeutic chemical (ATC) classification $^{13}$ and the Pharmaceutical Benefits Schedule (PBS) item codes. ${ }^{14}$ Services are coded according to the Medicare Benefits Schedule (MBS), ${ }^{15}$ and hospitalisations are coded according to the World Health Organization International Classification of Diseases, 10th revision, Australian modification (ICD-10AM). ${ }^{16}$

\section{Prevalence of clinical indicators in the DVA database}

Details of the development of the clinical indicators of suboptimal medication-related processes of care before hospitalisation have been published elsewhere. ${ }^{11}$ As an example of an indicator where the outcome of interest is hospitalisation for acute coronary syndrome, the associated process of care is defined as the combination of "patient has coronary artery stent (in 1 year before admission)" and "no use of aspirin or clopidogrel (in 12 months before admission)". ${ }^{11}$

We reviewed the clinical indicators to identify those that were suitable for testing with the DVA administrative health claims data. As the DVA database is an administrative claims dataset, it contains records only for medicines and health services that attract a subsidy. Health care activities that do not have an individual funding item number, such as blood pressure measurement, are not recorded in the administrative claims database. Although the use of health services (such as testing for glycated haemoglobin $\left[\mathrm{HbA}_{1 \mathrm{c}}\right]$ levels) can be determined from the claims data, the test results are not available. The criteria for appropriate use of health services as part of the process of care adopted by the indicators were based on practice recommendations in Australian evidence-based guidelines. ${ }^{11}$ Some of the validated indicators included processes of care that could not be identified in the administrative claims database, and therefore had to be excluded from this analysis. A total of 21 of the 29 validated indicators included medication-related processes of care that could be identified in the claims database and were therefore included in this analysis. They were drawn from six disease groupings: cardiovascular disease, respiratory disease, gastrointestinal disease, osteoporosis or fracture, renal disease, and diabetes. Of these 21 indicators, 13 are based on Level I evidence. ${ }^{11}$ Indicators that could not be included related to conditions that could not be accurately identified in the data: moderate to severe chronic obstructive pulmonary disease with frequent exacerbations, dyspepsia, and positive test results for Helicobacter pylori; influenza and pneumococcal vaccinations are not recorded in the database, nor are the doses of medicines used (corticosteroids) or the vitamin D or calcium levels. ${ }^{11}$

Data rules were developed for identifying each pattern of care and hospitalisation outcome for each indicator in the administrative claims dataset. These data rules included ICD-10-AM codes that identified each hospitalisation outcome, ATC or PBS item codes that identified medications, and MBS codes that identified testing procedures or claims related to the process of care. DVA administrative health claims between 1 July 2007 and 30 June 2012 were analysed to identify all hospitalisations with a primary diagnosis for the outcomes, and all MBS and PBS claims were analysed for patterns of care for the clinical indicator set.

We calculated the prevalence of hospitalisations with suboptimal medication-related processes of care before hospitalisation, as defined by the clinical indicator set. The prevalence was defined as the proportion of individuals with both the pattern of care and the associated hospitalisation divided by the total number of hospitalisations for that indicator. Demographic data were obtained for patients at study entry. All analyses were undertaken with SAS for Windows, v9.4 (SAS Institute).

\section{Results}

There were 164813 hospitalisations for the conditions included in the clinical indicator set over the 5-year study period, encompassing 83430 patients. The median age of the study population was 81 years (interquartile range, $78-84$ years); $54.5 \%$ were men, and $6.9 \%$ resided in an aged care facility at the time of admission (Box 1).

Box 2 contains the final list of clinical indicators included in the study and the prevalence of suboptimal medication-related processes of care preceding hospitalisation. More than one-third $(34.5 \%)$ of the study population had at least one hospitalisation and $10.4 \%$ had two or more hospitalisations involving suboptimal medication-related processes of care before admission (Box 1). The overall proportion of hospitalisations that were preceded by suboptimal medication-related processes of care was $25.2 \%$ (41546 hospitalisations). The most common hospitalisations were for cardiovascular disease (including acute coronary syndromes and heart failure), fracture and gastrointestinal conditions. Fracture and congestive heart failure (CHF) caused the highest numbers of hospitalisations that were preceded by suboptimal medication-related processes of care (Box 2). Of the fracture hospitalisations, $85.4 \%$ were for patients aged 65 years or older 
1 Demographics of the study population: hospitalisation for diagnoses in the medication-related clinical indicator set $(n=83430)$

Age, median (interquartile range)

81 years ( $78-84$ years)

Sex, $n(\%)$

Male

$45456(54.5 \%)$

Female

$37974(45.5 \%)$

Location of residence, $n$ (\%)

Residential aged care facility

5725 (6.9\%)

Community

$77705(93.1 \%)$

Hospitalisations with suboptimal processes of care before admission, $n$ (\%)

0

1

$\geq 2$
$54623(65.5 \%)$

$20167(24.2 \%)$

$8640(10.4 \%)$ who had been dispensed a falls-risk medicine before admission; $19.7 \%$ and $17.2 \%$ of fracture hospitalisations were for men and women, respectively, who had a history of fracture or osteoporosis but had not received a medicine for osteoporosis. There were $4744 \mathrm{CHF}$ admissions (17.1\%) of patients with a history of CHF who had not been dispensed an angiotensin-converting enzyme inhibitor (ACEI) or an angiotensin receptor blocker (ARB) in the 3 months before admission. More than one in 10 admissions for gastrointestinal bleeding or ulcer were associated with long-term use of non-steroidal anti-inflammatory drugs (NSAIDs). About one in 10 admissions for renal failure occurred in patients with a history of diabetes who had not received a renal function test in the year before admission and were not dispensed an ACEI or ARB (Box 2).

Although there were more than 33363 hospitalisations for acute coronary syndromes during the study period, less than $2 \%$ involved individuals with a history of myocardial infarction or who had received cardiac stents and had not been dispensed acute coronary syndrome medicines recommended by the guidelines. Similarly, although there were more than 17149 hospitalisations for gastrointestinal bleeding, ulcer or gastritis during the study period, less than $1 \%$ involved patients with a previous history of gastrointestinal bleeding or ulcer who had been dispensed an NSAID without a concurrent gastroprotective agent (Box 2). There were 1751 admissions for hyperglycaemia or hypoglycaemia; only 209 of these patients $(11.9 \%)$ were prescribed insulin and had not received an $\mathrm{HbA}_{1 \mathrm{c}}$ test in the 6 months before admission.

\section{Discussion}

This is the first study to examine suboptimal medication-related processes of care before hospitalisation. We applied newly developed evidence-based clinical indicators specific to the Australian health care setting and found that $25.2 \%$ of hospitalisations for conditions identified in the clinical indicator set were preceded by suboptimal medicationrelated processes of care. Of the 28807 patients in the study who had hospitalisations preceded by suboptimal medication-related processes of care, 30\% (8640 patients) had multiple such hospital admissions. At least one in 10 hospitalisations for $\mathrm{CHF}$, ischaemic stroke, asthma, gastrointestinal ulcer or bleeding, fracture, renal failure or nephropathy, hyperglycaemia or hypoglycaemia were preceded by suboptimal medication-related processes of care that clinicians should be able to identify and avoid. The frequency of fallsrisk medicine use before hospitalisation for a fracture was particularly high $(85.4 \%)$, highlighting the need to review appropriate prescribing of these medications for older people, who may be particularly vulnerable to their adverse effects.

A recent Australian study (CareTrack) examined the provision of appropriate health care. The investigation was based on medical records from health care practices (primary and secondary care) and hospitals, and it found that $43 \%$ of Australian patients had not received appropriate care. ${ }^{17}$ The CareTrack study examined process indicators only, and these were not linked to outcome measures, such as hospitalisation. The indicators included in the study were either consensus or evidencebased in nature, and were related to individual patient data. Gaps in the provision of appropriate care for specific conditions were identified (including for diabetes, osteoporosis, asthma and stroke), consistent with the results of our study.

Many of the conditions for which suboptimal processes of care were identified by our study fall within National Health Priority Areas for Australia or are associated with a high disease burden in Australia. ${ }^{18}$ This highlights the potential suitability of the medication-related indicators for monitoring appropriate provision of health care in Australia.

Other studies have highlighted the suitability of clinical indicators as quality indicators for monitoring health system performance and assessing the quality of patient care. $5,7,10$ Our study showed that administrative health databases can be used to investigate suboptimal medication-related processes of care before hospitalisation through the application of clinical indicators, and to assess the appropriateness of health care in current clinical practice. Routine prospective monitoring of trends in suboptimal processes of care associated with medicine use, and the use of the indicators in administrative health datasets or as data-mining tools in primary care, could provide a valuable tool for monitoring and improving health system performance. Primary care interventions, such as patient- 
2 Prevalence of hospitalisations after suboptimal processes of care as defined by the medication-related clinical indicator set

$\begin{array}{cc}\text { Hospitalisation } & \begin{array}{c}\text { Process of care } \\ \text { No. }\end{array} \\ \text { outcome } & \text { (preceding hospitalisation) }\end{array}$

Cardiovascular disease indicators

1 Acute coronary syndrome

2 Acute coronary syndrome

$3 \mathrm{CHF}$

5 Ischaemic stroke

1) History of myocardial infarction (in 2 years before admission)

2) Not on aspirin, $\beta$-blocker, ACEI or $A R B$ and statin (in 3 months before admission)

1) Patient has coronary artery stent (in 1 year before admission)

2) No use of aspirin or clopidogrel (in 12 months before admission)

1) History of CHF (in 2 years before admission) before admission )

1) History of CHF and heart block or advanced bradycardia (in 2 years before admission) admission)
2) Not on an ACEl or ARB (in 3 months

2) Use of digoxin (in 6 months before

1) History of chronic atrial fibrillation or ischaemic stroke (in 2 years before admission)

2) No use of warfarin or aspirin (in 3 months before admission)

Respiratory disease indicators

6 Asthma

1) History of asthma

2) Use of short-acting $\beta$-agonist more than three times per week

3) No use of inhaled corticosteroids

7 Asthma

1) History of asthma

2) Use of long-acting $\beta$-agonist

3) No use of inhaled corticosteroids

Gastrointestinal disease indicators

8 Gastrointestinal bleed, perforation or ulcer or gastritis

1) History of gastrointestinal ulcer or bleeding

2) NSAID use for at least 1 month

3) No use of gastroprotective agent (eg, proton pump inhibitor)

9 Chronic constipation or impaction

1) Regular use of a strong opioid analgesic (fentanyl, oxycodone, morphine)

2) No concurrent use of a laxative

10 Gastrointestinal ulcer or bleed

1) Patient with osteoarthritis

2) Dispensed long-term NSAID therapy (including cyclooxygenase-2 inhibitors)

\section{Osteoporosis or fracture indicators}

11 Fracture

1) Female patient

Hospitalisations after suboptimal care [\% TH, 95\% Cl]

640 [1.91\%, 1.75\%-2.05\%]

$4744[17.05 \%, 16.66 \%-17.54 \%]$

195 [0.63\%, 0.54\%-0.72\%]

677 [10.20\%, 9.47\%-10.93\%]

10 [0.75\%, 0.32\%-1.28\%]

107 [0.62\%, 0.48\%-0.72\%]

2) History of osteoporosis or fracture

3) No use of hormone replacement therapy, bisphosphonate, teriparatide, selective oestrogen receptor modulators or strontium 


\begin{tabular}{|c|c|c|c|c|c|}
\hline No. & $\begin{array}{l}\text { Hospitalisation } \\
\text { outcome }\end{array}$ & & $\begin{array}{c}\text { Process of care } \\
\text { (preceding hospitalisation) }\end{array}$ & $\begin{array}{l}\text { Total } \\
\text { hospitalisations } \\
\text { (TH) }\end{array}$ & $\begin{array}{l}\text { Hospitalisations after } \\
\text { suboptimal care } \\
{[\% \mathrm{TH}, 95 \% \mathrm{Cl}]} \\
\end{array}$ \\
\hline \multirow[t]{3}{*}{12} & \multirow[t]{3}{*}{ Fracture } & 1) & Male patient & \multirow[t]{3}{*}{12231} & \multirow[t]{3}{*}{2406 [19.67\%, 18.98\%-20.38\%] } \\
\hline & & 2) & History of osteoporosis or fracture & & \\
\hline & & 3) & No use of bisphosphonate or teriparatide & & \\
\hline \multirow[t]{2}{*}{13} & \multirow[t]{2}{*}{ Fracture } & 1) & Patient aged 65 years or older & \multirow[t]{2}{*}{31486} & \multirow[t]{2}{*}{26892 [85.41\%, 85.01\%-85.79\% } \\
\hline & & 2) & $\begin{array}{l}\text { Use of a falls-risk medicine } 6,7,24 \\
\text { (eg, long-acting hypnotic or anxiolytic, } \\
\text { tricyclic antidepressant) }\end{array}$ & & \\
\hline \multicolumn{6}{|c|}{ Renal disease indicators } \\
\hline \multirow[t]{3}{*}{14} & \multirow{3}{*}{$\begin{array}{l}\text { Renal failure or } \\
\text { nephropathy }\end{array}$} & 1) & History of diabetes & \multirow[t]{3}{*}{7335} & \multirow[t]{3}{*}{$665[9.07 \%, 8.44 \%-9.76 \%]$} \\
\hline & & 2) & $\begin{array}{l}\text { Microalbuminuria and plasma creatinine } \\
\text { not monitored in previous } 12 \text { months }\end{array}$ & & \\
\hline & & 3) & Patient not on ACEI or ARB & & \\
\hline \multirow[t]{2}{*}{15} & \multirow[t]{2}{*}{ Renal failure } & 1) & NSAID use for $>3$ months & \multirow[t]{2}{*}{7113} & \multirow[t]{2}{*}{102 [1.43\%, 1.13\%-1.67\%] } \\
\hline & & 2) & $\begin{array}{l}\text { Serum creatinine not monitored in } \\
\text { the previous } 12 \text { months }\end{array}$ & & \\
\hline \multicolumn{6}{|c|}{ Diabetes indicators } \\
\hline \multirow[t]{2}{*}{16} & \multirow{2}{*}{ Hyperglycaemia } & 1) & Use of an oral hypoglycaemic agent & \multirow[t]{2}{*}{223} & \multirow[t]{2}{*}{42 [18.83\%, 13.67\%-23.93\%] } \\
\hline & & 2) & $\begin{array}{l}\mathrm{HbA}_{1 c} \text { level not monitored in previous } \\
6 \text { months }\end{array}$ & & \\
\hline \multirow[t]{2}{*}{17} & \multirow[t]{2}{*}{ Hypoglycaemia } & 1) & $\begin{array}{l}\text { Use of a long-acting oral } \\
\text { hypoglycaemic agent (glibenclamide } \\
\text { or glimepiride) }\end{array}$ & \multirow[t]{2}{*}{1528} & \multirow[t]{2}{*}{67 [4.38\%, 3.37\%-5.43\%] } \\
\hline & & 2) & $\begin{array}{l}\mathrm{HbA}_{\mathrm{lc}} \text { level not monitored in the } \\
\text { previous } 6 \text { months }\end{array}$ & & \\
\hline \multirow[t]{2}{*}{18} & \multirow{2}{*}{$\begin{array}{l}\text { Hyperglycaemia or } \\
\text { hypoglycaemia }\end{array}$} & 1) & Use of insulin & \multirow[t]{2}{*}{1751} & \multirow[t]{2}{*}{209 [11.94\%, 10.38\%-13.42\%] } \\
\hline & & 2) & $\begin{array}{l}\mathrm{HbA}_{1 c} \text { level not monitored in the } \\
\text { previous } 6 \text { months }\end{array}$ & & \\
\hline \multirow[t]{3}{*}{19} & \multirow[t]{3}{*}{$\begin{array}{l}\text { Hyperglycaemia or } \\
\text { hypoglycaemia }\end{array}$} & 1) & $\begin{array}{l}\text { Use of insulin or oral hypoglycaemic } \\
\text { medicines }\end{array}$ & \multirow[t]{3}{*}{1751} & 103 [5.88\%, 4.80\%-7.01\%] \\
\hline & & 2) & $\begin{array}{l}\text { Use of medicines that may alter } \\
\text { blood glucose concentration }\end{array}$ & & \\
\hline & & 3) & $\begin{array}{l}\mathrm{HbA} \mathrm{Al}_{\mathrm{c}} \text { level not monitored in the } \\
\text { previous } 6 \text { months }\end{array}$ & & \\
\hline 20 & Hypoglycaemia & 1) & Use of glibenclamide or glimepiride & 1528 & $42[2.75 \%, 1.97 \%-3.63 \%]$ \\
\hline & & 2) & $\begin{array}{l}\text { Renal function not monitored in the } \\
\text { previous year }\end{array}$ & & \\
\hline 21 & Cardiovascular & 1) & History of diabetes & 67177 & 2541 [3.78\%, 3.66\%-3.94\%] \\
\hline & disease & 2) & Not on lipid-lowering drug & & \\
\hline
\end{tabular}

$\mathrm{ACEI}=$ angiotensin-converting enzyme inhibitor; $\mathrm{ARB}=$ angiotensin receptor blocker; $\mathrm{CHF}=$ congestive heart failure; $\mathrm{HbA}_{\mathrm{Ic}}=$ glycated haemoglobin; NSAID = non-steroidal anti-inflammatory drug.

specific feedback to medical practitioners, could focus on improving processes of care that have known and significant risks for patient outcomes and health care expenditure.

The suboptimal processes of care associated with the medicationrelated indicators applied in our study were validated by an expert panel as problems that clinicians should be able to recognise as suboptimal, with adverse outcomes that are foreseeable, and which could be identified and controlled. Collaborative home medicines reviews that involve the patient, the pharmacist and the general practitioner have been shown to increase the identification and resolution of medicationrelated problems, ${ }^{19}$ and to reduce hospitalisation of patients with heart failure $^{20}$ and those taking warfarin. ${ }^{21}$ The suboptimal care processes leading to hospitalisation outcomes in our study are the types of problems that could be identified and potentially resolved with a medication review (eg, reviewing the use of laxatives by chronic users of opioids or of falls-risk medications). Future research could be conducted to confirm whether such reviews are effective in reducing the incidence of suboptimal medication-related processes of care. 
A limitation of our study is that we did not assess whether implementation of appropriate care processes would have avoided hospitalisation. It may be that hospitalisations would still have occurred even if the appropriate pattern of care had been implemented. Of interest for future studies would be an examination of the occurrence and effect on hospital admissions of the care processes defined by the indicator set. In addition, there may be a subset of patients in the study population for whom certain medications are contraindicated, possibly related to comorbid conditions that we were not able to identify. An additional limitation was the inability to distinguish between individuals with diastolic and systolic heart failure on the basis of the available data; we acknowledge that the evidence base for the efficacy of ACEIs and ARBs in reducing long-term morbidity and mortality in those with diastolic heart failure is currently lacking. ${ }^{22}$ Furthermore, we were unable to assess the use of over-the-counter medicines.

Our study analysed DVA administrative data, which cover an older population of patients with a median age of 81 years. However, our results are probably applicable to other older Australians. Age-specific comparisons of DVA Gold Card holders (those eligible for all health services subsidised by the DVA) without service-related disability with the wider Australian population have found similar rates of GP visits, filling of prescriptions, and hospitalisations per year. $^{23}$

Although differences in the definitions of clinical indicators may limit their applicability to other population groups, the indicators we used are based on high-level evidence for common chronic conditions and are linked to patient outcomes. More than $60 \%$ of the indicators examined were based on Level I evidence, which, where applicable, included clinical studies of those aged 75 years or older (eg, the use of antiosteoporosis medicines to reduce the incidence of fractures). ${ }^{11}$

In summary, this study highlights conditions associated with suboptimal medication-related processes of care in the primary care setting. The patterns of care on which the indicators are based incorporate high-level evidence and are therefore likely to be applicable internationally. Failure to implement appropriate patterns of care suggests that an opportunity to improve health care outcomes is being missed. Routine prospective monitoring of the prevalence of suboptimal processes of care and adverse outcomes in the Australian health care system by means of these clinical indicators may provide a method for assessing the appropriateness of care for common chronic conditions and identifying evidence-practice gaps in primary care. The results could be used to inform and focus the development of interventions and efforts to improve the quality of health care delivery, potentially reducing morbidity and health care costs.

Acknowledgements: This research was funded by the BUPA Health Foundation. We thank the expert clinical panel and the project advisory group for their time and expertise. We thank the Department of Veterans' Affairs for providing the administrative claims data used in this study.

Competing interests: No relevant disclosures.

(C) 2015 AMPCo Pty Ltd. Produced with Elsevier B.V. All rights reserved. 
1 Australian Institute of Health and Welfare. Chronic diseases and associated risk factors in Australia, 2006. Canberra: AlHW, 2006. (AlHW Cat. No. PHE 81.) http://www.aihw.gov. au/publication-detail/?id $=6442467$ 914 (accessed Apr 2014).

2 Australian Institute of Health and Welfare. Health expenditure Australia, 2010-11. Health and welfare expenditure series no. 47. Canberra: AlHW, 2012. (AlHW Cat. No. HWE56.) http://www.aihw.gov.au/WorkArea/ DownloadAsset.aspx?id=10737423003 (accessed Apr 2014).

3 Roughead L, Semple S, Rosenfeld E. Literature review: medication safety in Australia. Sydney: Australian Commission on Safety and Quality in Health Care, 2013. http://www. safetyandquality.gov.au/wp-content/ uploads/2013/08/Literature-ReviewMedication-Safety-in-Australia-2013. pdf (accessed Mar 2013).

4 Australian Institute of Health and Welfare. Australian hospital statistics 2011-12. Health services series no. 50 . Canberra: AlHW, 2013. (AlHW Cat. No. HSE 134.) http://www.aihw.gov.au/ WorkArea/DownloadAsset.aspx?id=6 0129543146 (accessed Jun 2014).

5 Robertson $\mathrm{H}$, Mackinnon $\mathrm{N}$. Development of a list of consensusapproved clinical indicators of preventable drug-related morbidity in older adults. Clin Ther 2002; 24: 1595-1613.

6 Morris CJ, Cantrill JA, Hepler CD, Noyce PR. Preventing drug-related morbidity - determining valid indicators. Int J Qual Health Care 2002; 14: 183-198.

7 Mackinnon NJ, Hepler CD. Indicators of preventable drug-related morbidity in older adults 2. Use within a managed care organization. J Manag Care Pharm 2003; 9: 134-141.

8 Saver B, Hepler CD, Cherney B, Williamson J. Computerized indicators of potential drug-related emergency department and hospital admissions. Am J Manag Care 2007; 13: 29-35.

9 Kalisch LM, Caughey GE, Barratt JD, et al. Prevalence of preventable medication-related hospitalisations in Australia: an opportunity to reduce harm. Int J Qual Health Care 2012; 24: 239-249.

10 Mainz J. Quality indicators: essential for quality improvement. Int J Qual Health Care 2004; 16(s1): il-i2.
1 Caughey GE, Kalisch Ellett LM, Wong TY. Development of evidence based Australian medication-related indicators of potentially preventable hospitalisations: a modified RAND appropriateness method. BMJ Open 2014; 4: e004625.

12 Hepler CD, Strand LM. Opportunities and responsibilities in pharmaceutical care. Am J Hosp Pharm 1990; 47: 533-543.

13 WHO Collaborating Centre for Drug Statistics Methodology. ATC/DDD index 2015. http://www.whocc.no/atc_ ddd_index/ (accessed Jun 2015).

14 Australian Government Department of Health. Pharmaceutical Benefits Scheme (PBS). 2015. http://www.pbs. gov.au/pbs/home (accessed Apr 2015).

15 Australian Government Department of Health and Ageing. The December 2012 Medicare Benefits Schedule. Canberra: Department of Health and Ageing, 2012. http://www.health.gov.au/ internet/mbsonline/publishing.nsf/ Content/Downloads-201212 (accessed Jan 2013).

16 Australian Consortium for Classification Development. ICD-10-AM/ACHI/ACS. Sydney: National Centre for Classification in Health, 2015. https:// www.accd.net.au/lcd10.aspx (accessed Jun 2015).

17 Runciman WB, Hunt TD, Hannaford NA, et al. CareTrack: assessing the appropriateness of health care delivery in Australia. Med J Aust 2012; 197: 100-105. https://www. mja.com.au/journal/2012/197/2/ caretrack-assessing-appropriatenesshealth-care-delivery-australia

18 Australian Institute of Health and Welfare. National Health Priority Areas. Canberra: AlHW, 2012. http://www. aihw.gov.au/national-health-priorityareas/ (accessed Jun 2012).

19 Gilbert AL, Roughead EE, Beilby J, et al. Collaborative medication management services: improving patient care. Med J Aust 2002; 177: 189-192. https://www.mja.com.au/ journal/2002/177/4/collaborativemedication-management-servicesimproving-patient-care

20 Roughead EE, Barratt JD, Ramsay EN, et al. The effectiveness of collaborative medicine reviews in delaying time to next hospitalisation for heart failure patients in the practice setting: results of a cohort study. Cir Heart Fail 2009; 2: 424-428.
21 Roughead EE, Barratt JD, Ramsay EN, et al. Collaborative home medicines review delays time to next hospitalisation for warfarin associated bleeding in Australian war veterans. J Clin Pharm Ther 2011; 36: 27-32.

22 National Heart Foundation of Australia and the Cardiac Society of Australia and New Zealand (Chronic Heart Failure Guidelines Expert Writing Panel). Guidelines for the prevention, detection and management of chronic heart failure in Australia. Updated October 2011. http://www. heartfoundation.org.au/ SiteCollectionDocuments/Chronic Heart_Failure_Guidelines_2011.pdf (accessed Apr 2012).

23 Australian Institute of Health and Welfare. Health care usage and costs. A comparison of veterans and war widows and widowers with the rest of the community. Canberra: AlHW, 2002. (AlHW Cat. No. PHE42.) http://www. aihw.gov.au/WorkArea/ DownloadAsset.aspx?id=6442459409 (accessed Jun 2014).

24 Hartikainen S, Lönnroos E, Louhivuori K. Medication as a risk factor for falls: critical systematic review. J Gerontol A Biol Sci Med Sci 2007; 62: 1172-1181. 